\title{
Enhancement of heat transfer using varying width twisted tape inserts
}

\author{
S. Naga Sarada ${ }^{1}$, A.V. Sita Rama Raju ${ }^{1}$, K. Kalyani Radha ${ }^{2}$, L. Shyam Sunder ${ }^{1}$ \\ ${ }^{l}$ Department of Mechanical Engineering, JNTUH College of Engineering, Hyderabad, A.P, INDIA \\ ${ }^{2 *}$ Sri Sai College of Engineering and Technology, Loluru(V), Anantapur(Dist.), A.P, INDIA \\ ${ }^{*}$ Corresponding Author: e-mail: kalyaniradha@gmail.com,Tel+91-944051772
}

\begin{abstract}
The present work shows the results obtained from experimental investigations of the augmentation of turbulent flow heat transfer in a horizontal tube by means of varying width twisted tape inserts with air as the working fluid. In order to reduce excessive pressure drops associated with full width twisted tape inserts, with less corresponding reduction in heat transfer coefficients, reduced width twisted tapes of widths ranging from $10 \mathrm{~mm}$ to $22 \mathrm{~mm}$, which are lower than the tube inside diameter of $27.5 \mathrm{~mm}$ are used. Experiments were carried out for plain tube with/without twisted tape insert at constant wall heat flux and different mass flow rates. The twisted tapes are of three different twist ratios $(3,4$ and 5$)$ each with five different widths (26-full width, 22, 18, 14 and $10 \mathrm{~mm}$ ) respectively. The Reynolds number varied from 6000 to 13500 . Both heat transfer coefficient and pressure drop are calculated and the results are compared with those of plain tube. It was found that the enhancement of heat transfer with twisted tape inserts as compared to plain tube varied from 36 to $48 \%$ for full width (26mm) and 33 to $39 \%$ for reduced width $(22 \mathrm{~mm})$ inserts. Correlations are developed for friction factors and Nusselt numbers for a fully developed turbulent swirl flow, which are applicable to full width as well as reduced width twisted tapes, using a modified twist ratio as pitch to width ratio of the tape.
\end{abstract}

Keywords: Enhancement; heat transfer; twisted tape inserts; turbulent; swirling; pressure drop

\section{Introduction}

Among many techniques (both passive and active) investigated for augmentation of heat transfer rates inside circular tubes, a wide range of inserts has been utilized, particularly when turbulent flow is considered. The inserts studied included coil wire inserts, brush inserts, mesh inserts, strip inserts, twisted tape inserts etc. Augmentation of convective heat transfer in internal flows with tape inserts in tubes is a well-acclaimed technique employed in industrial practices.

Hsieh and Huang (2000) conducted experimental studies for heat transfer and pressure drop of laminar flow in horizontal tubes with/without longitudinal inserts. They reported that enhancement of heat transfer as compared to a conventional bare tube at the same Reynolds number to be a factor of 16 at $R e \leq 4000$, while a friction factor rise of only 4.5. A new method was postulated by (Sarma et al., 2003) to predict heat transfer coefficients with twisted tape inserts in a tube in which the wall shear and the temperature gradients were properly modified through friction coefficient correlation leading to heat transfer augmentation from the tube wall. Experimental studies on heat transfer and flow characteristics for turbulent flow of air in a horizontal circular tube with strip type insert (longitudinal and Crossed Strip inserts). They reported that friction factor rise due to inclusion of inserts was typically between 1.1 and 1.5 from low $\operatorname{Re}(=6500)$ to high $\operatorname{Re}(=19500)$ with respect to bare tube (Hsieh et al., 2003). Experimental investigations for the heat transfer characteristics and the pressure drop in horizontal double pipes with twisted tape inserts were carried out (Naphon, 2006). Heat transfer, friction factor and enhancement efficiency characteristics in a circular tube fitted with conical ring turbulators and a twisted-tape swirl generator were investigated experimentally (Promvonge and Eiamsaard, 2007).

Monheit (1987) made a comparative study of the thermal performance of ordinary full-width full-length twisted tapes with tapes having modified surface configurations. Dasmahapatra and Rao (1991) studied augmentation of heat transfer to viscous nonNewtonian fluids in laminar flow using full width interrupted twisted tapes under the uniform wall temperature condition. AlFahed and Chakroun (1996) investigated the effect of tube-tape clearance on heat transfer under fully developed turbulent flow 
conditions in a horizontal isothermal tube. Investigations were carried out on twisted tape inserts in viscous flow in a horizontal tube (Manglik and Bergles, 1992). Experimental data were obtained for water and ehtylene glycol with snug-fit tape inserts of three different twist ratios, $y=3.0,4.5$, and 6.0 ; the tape thickness in each case was $0.483 \mathrm{~mm}$. In continuation of their research, an extended review of the application of twisted-tape inserts in tubular heat exchangers and their thermal-hydraulic performance was discussed (Manglik and Bergles, 2003). Twisted tapes promote enhanced heat transfer by generating swirl or secondary flows, increasing the flow velocity due to the tube partitioning and blockage. Experiments were conducted on compound heat transfer enhancement in a tube fitted with serrated twisted tape in the Reynolds number range of 5000 to 25000 (Chang et al., 2007). Heat transfer and pressure drop characteristics of laminar flow in rectangular and square plain ducts and ducts with twisted-tape inserts were experimentally investigated by (Saha and Mallick, 2005).

Experimental investigation of heat transfer and friction factor characteristics of circular tube fitted with full-length helical screw element of different twist ratio, and increasing and decreasing order of twist ratio set have been studied with uniform heat flux (Sivashanmugam and Suresh, 2006). Empirical correlations were developed in terms of twist ratio and Reynolds number. In continuation of their research, investigations on the heat transfer and friction factor characteristics of a circular tube fitted with a full-length helical screw element with different twist ratios (Sivashanmugam and Suresh, 2007). They performed their experiments for various Reynolds numbers and the obtained experimental data were then compared with those previously reported in the literature. They reported higher performance of the helical twisted insert in comparison with the twisted tape insert.

Modification of twisted tape was made by focusing on the increase of heat transfer rate rather than the reduction of friction loss, for example, the jagged (Rahimi et al., 2009) broken (Chang et al., 2007) and serrated (Chang and Jan, 2007) twisted tapes. The tapes in this group were designed to offer stronger swirl flow and better mixing than the typical one. However, the enhanced heat transfer by the use of the twisted tapes in the group was certainly accompanied by the rise of friction factor. In general, the performance factors of twisted tapes in this group were higher.

Experimental studies were carried out on the heat transfer enhancement and pressure drop characteristics in presence of twisted tape inserts, during flow boiling of R-134a inside a horizontal evaporator for plain flow and four tubes with twisted tapes of 6,9, 12 and 15 twist ratios and four refrigerant mass velocities of 54, 85, 114 and $136 \mathrm{~kg} / \mathrm{s} \mathrm{m}^{2}$ for each tape. It has been found that the twisted tape inserts enhance the heat transfer coefficient on relatively higher pressure drop penalty, in comparison to that for the plain tube flow (Kumar et al., 2009). Experimental studies for tubes fitted with Left - Right twisted tape inserts of various twist ratios to enhance the convective heat transfer rates for thermosyphon solar water heater system (Jaisankar et al., 2008). Experimental investigations were carried out on the heat transfer enhancement and pressure drop characteristics in the presence of twisted tape inserts, during flow boiling of R-134a, inside a horizontal evaporator (Akhavan-Behabadi et al., 2009).

Experimental investigations on circular tube fitted with full length twisted tape with trapezoidal-cut were studied for the Reynolds number range of 2000-12000 (Murugesan et al., 2009). A significant increase in heat transfer coefficient and friction factor for tape with trapezoidal-cut was observed. Experimental investigation on heat transfer and friction factor characteristics of circular tube fitted with right-left helical screw inserts of equal length, and unequal length of different twist ratio have been presented (Sivashanmugam and Nagarajan, 2007). The results shows that the heat transfer coefficient enhancement for right-left helical screw inserts is higher than that for straight helical twist for a given twist ratio. The relationship between the intensity of secondary flow and the intensity of laminar convective heat transfer is studied using a numerical method (Lin et al., 2009). The results reveal that the cross-averaged absolute vorticity flux in the main flow direction can reflect the intensity of secondary.

Experimental studies were conducted in a round tube with short-length twisted tape insert on the mean Nusselt number, friction factor and enhancement efficiency characteristics under uniform wall heat flux boundary conditions (Eiamsa-ard et al, 2009). The short-length tape is introduced as a swirling flow device for generating a strong swirl flow at the tube entry while the full-length twisted tape is inserted into the tested tube at a single twist ratio of $y / w=4.0$. The enhancement efficiency of the tube with the short-length tape insert is found to be lower than that with the full-length one. In continuation, investigations were carried out in a tube equipped with the combined devices between the twisted tape (TT) and constant/ periodically varying wire coil pitch ratio (Eiamsa-ard et al., 2010a). The highest thermal performance factor of around 1.25 is found by using DI-coil in common with the TT at lower Reynolds number. Also experiments were performed using single twisted tapes and full-length dual twisted tapes with three different twist ratios $(\mathrm{y} / \mathrm{w}=3.0,4.0$ and 5.0) and also regularly-spaced dual twisted tapes with three different space ratios $(\mathrm{s} / \mathrm{D}=0.75,1.5$ and 2.25). The effects of major parameters on heat transfer and friction factor are discussed. The result shows that the heat transfer of the tube with dual twisted tapes is higher than that of the plain tube with/without single twisted tape insert (Eiamsa-ard et al., 2010b).

Heat transfer, flow friction and thermal performance factor characteristics in a tube fitted with delta-winglet twisted tape, using water as working fluid are investigated experimentally for oblique delta-winglet twisted tape (O-DWT) and straight delta-winglet twisted tape (S-DWT) arrangements over a Reynolds number range of 3000-27,000 by considering three twist ratios (y/w $=3,4$ and 5) and three depth of wing cut ratios $(\mathrm{DR}=\mathrm{d} / \mathrm{w}=0.11,0.21$ and 0.32) (Wongcharee et al., 2010). The results show that Nusselt number and mean friction factor in the tube with the delta-winglet twisted tape increase with decreasing twisted ratio (y/w) and increasing depth of wing cut ratio.

Patil (2000) studied the frictional and heat transfer characteristics of laminar swirl flow of pseudo plastic type power law fluid in a circular tube using varying width twisted tapes under a uniform wall temperature condition. Reduced width twisted tape inserts gave $18 \%-56 \%$ lower isothermal friction factors than the full width tapes. Nusselt numbers decreased only slightly by $5 \%$ and 
$25 \%$, for tape widths of 19.7 and $11.0 \mathrm{~mm}$, respectively inside a $25 \mathrm{~mm}$ diameter tube. Also, the reduced width tapes offered $20 \%-$ $50 \%$ savings in the tape material as compared to the full width tapes, which is more economical.

The present investigation is aimed at studying the frictional and heat transfer characteristics in turbulent region using varying width twisted tape inserts under constant wall heat flux. The objective of using varying (reduced) width twisted tapes is to reduce the pressure drops associated with full width twisted tapes without seriously impairing the heat transfer augmentation rates and to achieve material savings.

\section{Materials and Methods}

The apparatus consists of a blower unit fitted with a pipe, which is connected to the test section located in horizontal orientation. Nichrome bend heater encloses the test section to a length of a $40 \mathrm{~cm}$. Four thermocouples T2, T3, T4 and T5 at a distance of $5 \mathrm{~cm}$, $15 \mathrm{~cm}, 25 \mathrm{~cm}$ and $35 \mathrm{~cm}$ from the origin of the heating zone are embedded on the walls of the tube and two thermocouples are placed in the air stream, one at the entrance (T1) and the other at the exit (T6) of the test section to measure the temperature of flowing air as shown in Figure 1. The pipe system consist a valve, which controls the airflow rate through it and an orifice meter to find the volume flow rate of air through the system. The diameter of the orifice is $14 \mathrm{~mm}$ with coefficient of discharge 0.64 .

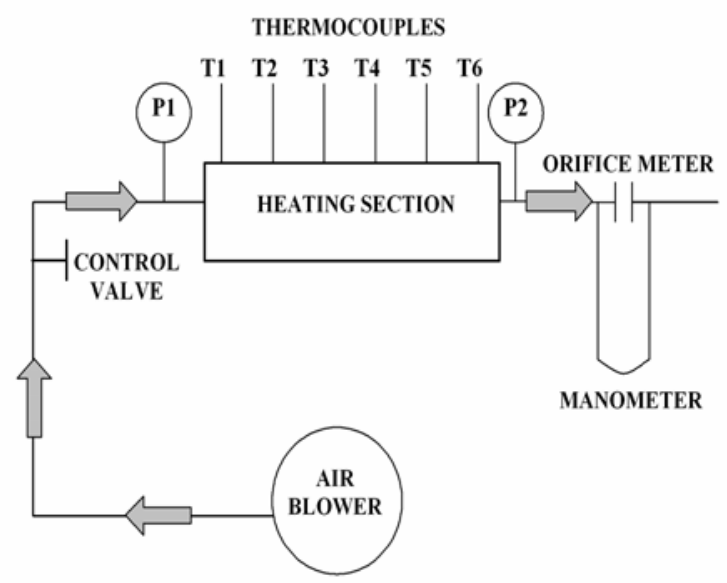

Figure 1: Experimental Set up Layout

Two calibrated pressure gauges ( $\mathrm{P} 1$ and $\mathrm{P} 2$ range: $0-1000 \mathrm{~mm}$ of water column) are provided to measure the pressure drops across the test section. Input to heater is given through dimmer stat. The inner tube of the heating part, which is the test tube with inside diameter $27.5 \mathrm{~mm}$, is made of $3.2 \mathrm{~mm}$ thick copper plate. Display unit consists of voltmeter, ammeter and temperature indicator. The circuit was designed for a load voltage of 0-220 V, with a maximum current of 10A. Difference in the levels of manometer fluid represents the variations in the flow rate of air. The velocity of airflow in the tube is measured with the help of orifice plate and the water manometer fitted on board.

\subsection{Materials}

The layout of tubes containing full width and the reduced width twisted tapes is shown in Figure 2. The tapes consist of uniformly long aluminium strips of desired width, which have been twisted about the longitudinal axis. Twisted tapes of five different widths $(26,22,18,14$ and $10 \mathrm{~mm})$ were fabricated for each of the three different pitches viz. 82.5, 110, and $137.5 \mathrm{~mm}$ as shown in Figure 2. For the case of reduced width tapes, the gap between the tube wall and the tape was maintained constant throughout the tube length. The tapes of full width $(26 \mathrm{~mm})$ were inserted as is into a $27.5 \mathrm{~mm}$-dia tube to give a sliding fit.

\subsection{Experimental Procedure}

Supply is given to the blower motor and the valve is opened slightly. A heat input of $40 \mathrm{w}$ is given to the nichrome heating wire wound on the test section by adjusting the dimmer stat. Thermocouples 2 to 5 are fixed on the test surface and thermocouples 1 to 6 are fixed inside the pipe. Thermocouples used for experimentation are J-type with an accuracy $\pm 0.2 \%$. The readings of the thermocouples are observed every 5 minutes until they show constant values. Under steady state condition, the readings of all the six thermocouples are recorded. The experiment is repeated for different openings of the valve, thus varying the airflow rate. The fluid properties were calculated as the average between the inlet and the outlet bulk temperature. It took 110 minutes to reach steady state conditions. Experiment was carried out at constant heat flux conditions and constant heat input of $40 \mathrm{w}$ at different mass flow rates.

Initially the experiment is carried out without any insert (plain tube experiment). The working fluid air flows through the pipe section with least resistance. The experiment is carried out in similar fashion with straight tape inserts, with twisted tape inserts 
with twist ratios (pitch/diameter) 3, 4 and 5 for widths of 26, 22, 18, 14 and $10 \mathrm{~mm}$. the inserts are made of aluminium. The mass flow rates considered for the constant heat input of $40 \mathrm{w}$ in terms of water level difference in U-tube water manometer are 2 inch, 3 inch, 4 inch and 5 inches (air mass flow rate varying from 0.0033 to $0.0055 \mathrm{~kg} / \mathrm{sec}$ ). Different types of inserts used are shown in Table 1. Each insert in table 1 is experimentally investigated for three different mass flow rates of air. Each insert is taken and inserted into the test section axially. It is taken care that the strip doesn't scratch the inner wall of the pipe and get deformed. The presence of the insert in the pipe causes resistance to flow and increases turbulence. For the case of reduced width tapes, the gap between the tube wall and the tape was maintained constant throughout the tube length by brazing metal pins to the edges of the tape.

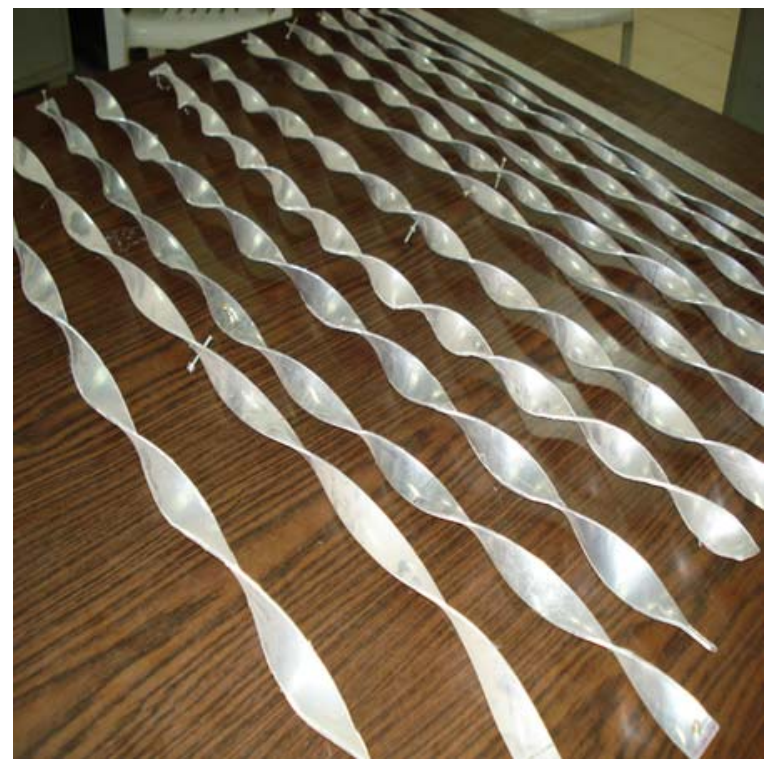

Figure 2: Photographs of twisted tape inserts

Table 1. Shows the different types of inserts used

\begin{tabular}{|c|c|c|}
\hline S.No & Twist Ratio (T.R) & Width of Tape insert (mm) \\
\hline 1 & 3,4 and 5 & $26,22,18,14$ and 10 \\
\hline 2 & Straight tape & $26,22,18,14$ and 10 \\
\hline 3 & Plain tube & ------------ \\
\hline
\end{tabular}

\subsection{Experimental Uncertainty}

Experiments were conducted initially for plain tube without inserts for different mass flow rates of air.

\section{Plain tube}

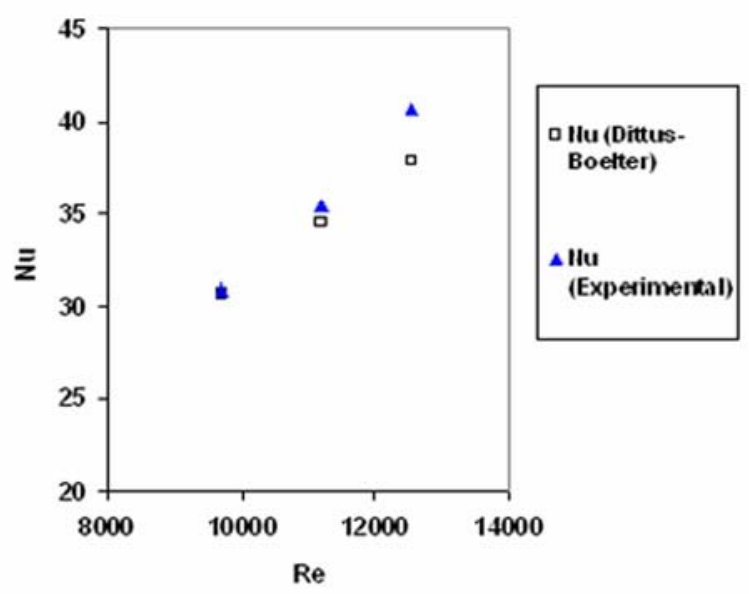

Figure 3: Comparison of Nusselt number for plain tube 


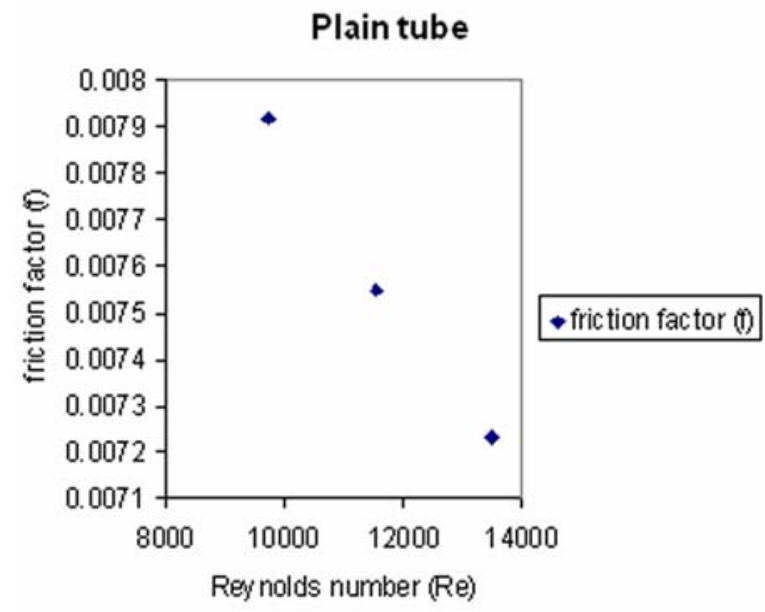

Figure 4: Variation of friction factor with Reynolds number for plain tube

The Nusselt number obtained from experimental work is compared with the value obtained using Dittus-Boelter equation (theoretical) (Figure 3). It is seen that the experimental results are in good agreement with aforementioned studies and $\mathrm{Nu}$ (experimental) is less than $\mathrm{Nu}$ (Dittus-Boelter). Actual heat carried away by air passing through the test section is the combination of convective and radiative heat transfers. As the heat transferred by convection alone is considered while performing numerical calculations (Eq. 8), it can be expected that $\mathrm{Nu}$ (experimental) is less than $\mathrm{Nu}$ (Dittus-Boelter).The experimental uncertainty is found as $7.6 \%$ for Nusselt number. From Figure 4. Friction factor is observed to reduce with increase in Reynolds number for plain tube.

\section{Heat Transfer Calculations}

$T s=(T 2+T 3+T 4+T 5) / 4$

$T b=(T 1+T 6) / 2$

Equivalent height of air column, $h_{a i r}=\left(\rho_{w} * h_{w}\right) / \rho_{a}$

Discharge of air, $d=C_{d} A_{p} A_{o} \sqrt{ }\left(2 g h_{\text {air }}\right) / \sqrt{ }\left(A_{p}{ }^{2}-A_{o}{ }^{2}\right)$

Velocity of air flow, $U=d / A p$

Reynolds number, $R e=U D / v$

(To calculate Re while using tape inserts, $D_{h}$ instead of $D$ is used)

$$
\begin{aligned}
& N u_{\text {the }}=0.023 \operatorname{Re}^{0.8} \operatorname{Pr}^{0.4} \\
& \mathrm{Q}=\mathrm{m}^{*} \mathrm{C}_{\mathrm{p}} *(T 1-T 6) \\
& Q r=\sigma^{*} A^{*} \varepsilon_{C}{ }^{*}\left(T s^{4}-T b^{4}\right) \\
& H=(Q-Q R) /(A(T S-T B)) \\
& N u=h D / K
\end{aligned}
$$

(To calculate $N u$ while using tape inserts, $D_{h}$ instead of $D$ is used)

$$
\begin{aligned}
& f_{\text {the }}=0.25\left(1.82 * \log _{10} R e_{D}-1.64\right)^{-2} \\
& f=\Delta P /\left((L / D)\left(\rho_{a} U^{2} / 2\right)\right) \\
& \eta=\left(N u_{i} / N u\right) /\left(f_{i} / f\right)^{0.333}
\end{aligned}
$$




\section{Results and Discussion}

\subsection{Heat Transfer and Overall Enhancement Characteristics}

The variation of Nusselt number with Reynolds number for straight tape inserts is shown in Figure 5. Highest Nusselt number was obtained for full width straight tape. The mean heat transfer gain for straight tape inserts varied from 4 to $24 \%$ compared to plain tube. This is due to strong turbulence intensity generated by tape inserts leading to rapid mixing of the flow causing heat transfer enhancement.

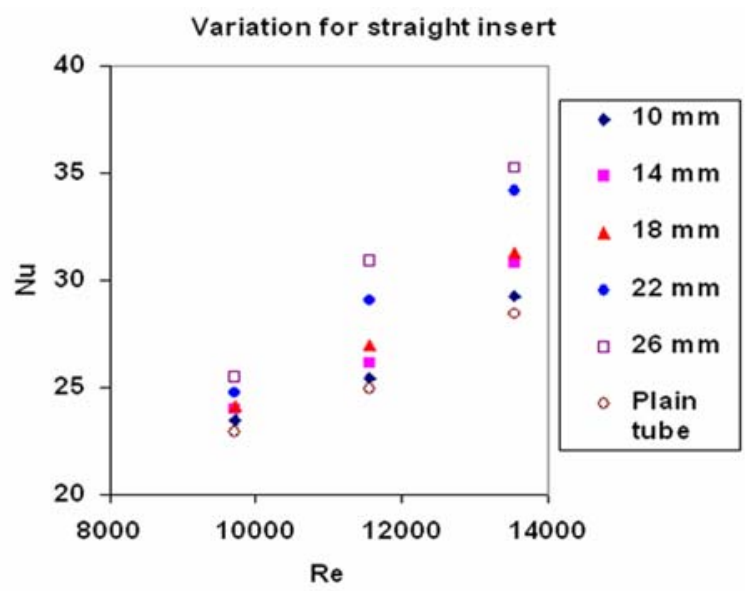

Figure 5: Variation of Nusselt number with Reynolds number for straight tape inserts

The variations of friction factor with Reynolds number for straight tape inserts are presented in Figure 6. It is observed that the friction factor gradually reduced with rise in Reynolds number. It is observed to be maximum for full width straight tape insert.

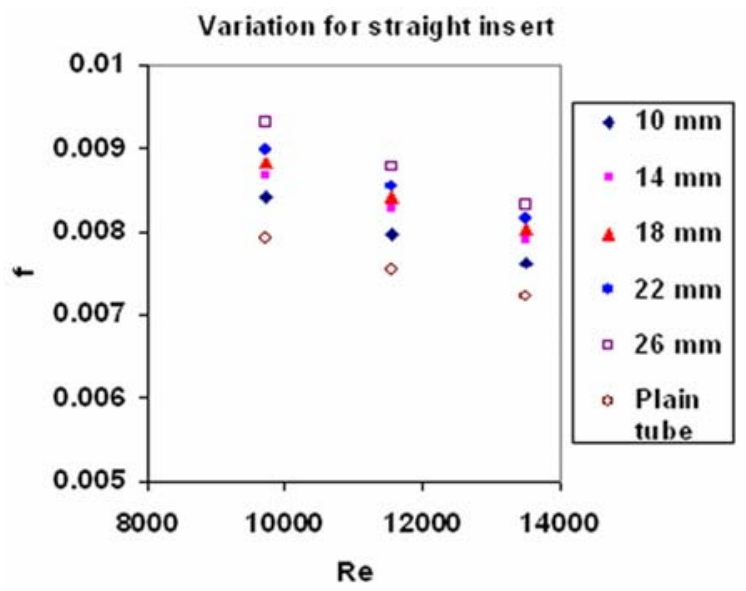

Figure 6: Variation of friction factor with Reynolds number for straight inserts

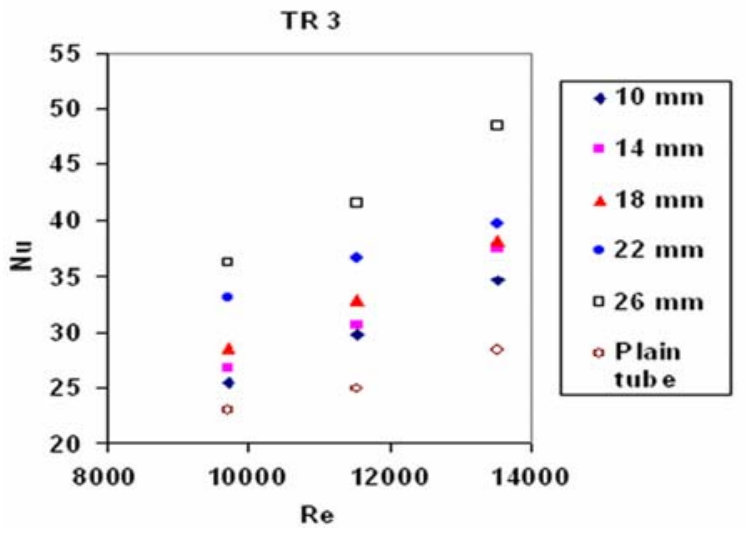

Figure 7: Variation of Nusselt number with Reynolds number for twist ratio=3 
It is evident from Figures 7,8 and 9 that when a twisted tape is inserted into a plain tube there is a significant improvement in Nusselt number because of secondary flow, with greater enhancement being realized at higher Reynolds numbers and lower twist ratios. This enhancement is mainly due to the centrifugal forces resulting from the spiral motion of the fluid and partly due to the tape acting as fin. It is observed that the reduction in tape width causes reduction in Nusselt numbers as well as reduction in pressure drop. From Figure 7, the percentage increase in Nusselt numbers for reduced width tapes compared to plain tube are about $11-22 \%, 16-31 \%, 24-34 \%$ and 39-44\% respectively for tape widths of 10, 14, 18 and 22 mm respectively for twist ratio $=3$. For full width tapes, the percentage increase is observed to be 58 to $70 \%$ compared to plain tube. From Figure 8 , the percentage increase in Nusselt numbers for reduced width tapes compared to plain tube are about 5-12\%, 9-22\%, 13-30\% and 23-36\% respectively for tape widths of 10, 14, 18 and $22 \mathrm{~mm}$ respectively for twist ratio $=4$. For full width tapes, the percentage increase is observed to be 36 to $42 \%$ compared to plain tube.

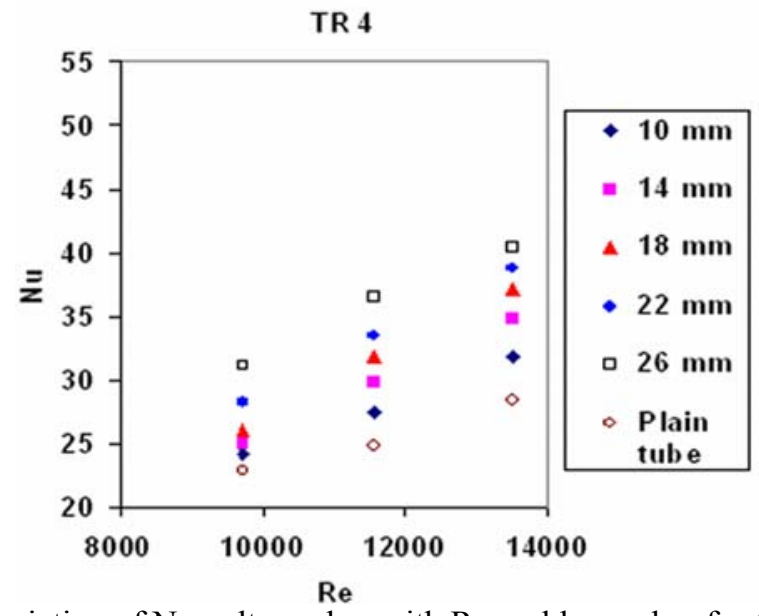

Figure 8: Variation of Nusselt number with Reynolds number for twist ratio $=4$

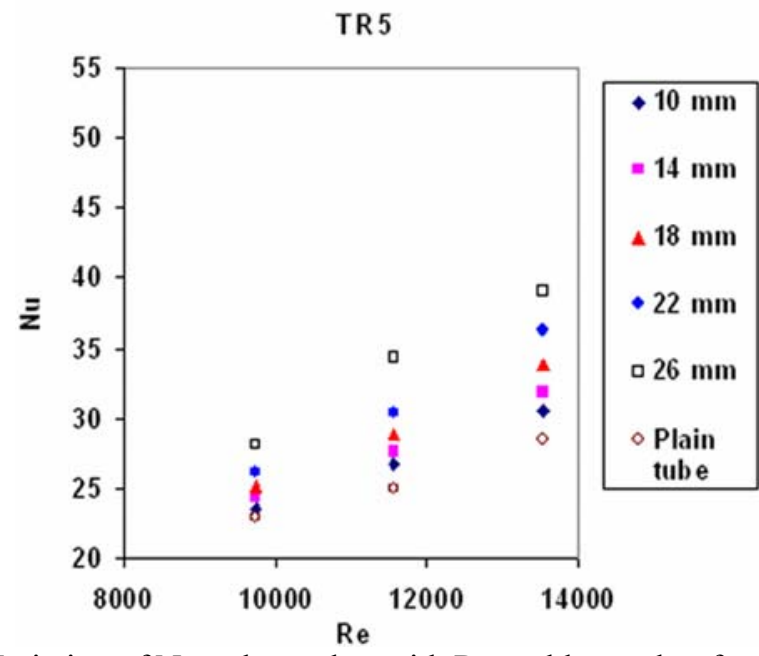

Figure 9: Variation of Nusselt number with Reynolds number for twist ratio $=5$

From Figure 9, the percentage increase in Nusselt numbers for reduced width tapes compared to plain tube are about 2-8\%, 6$12 \%, 9-19 \%$ and $14-27 \%$ respectively for tape widths of 10, 14, 18 and $22 \mathrm{~mm}$ respectively for twist ratio $=5$. For full width tapes, the percentage increase is observed to be 22 to $37 \%$ compared to plain tube. The overall enhancement ratio is useful to evaluate the quality of heat transfer enhancement obtained over plain tube at constant pumping power. It is found to be more than unity for all the tape inserts used. Variations of over all enhancement ratio $\eta$ against Reynolds number for twist ratios 3, 4 and 5 are shown in Figures 10, 11 and 12 respectively. It is observed that overall enhancement ratio tended to decrease gradually with the rise of Reynolds number for all twist ratios. The maximum value of over all enhancement ratio is 1.62 for full width twisted tape insert with twist ratio equal to 3 . 


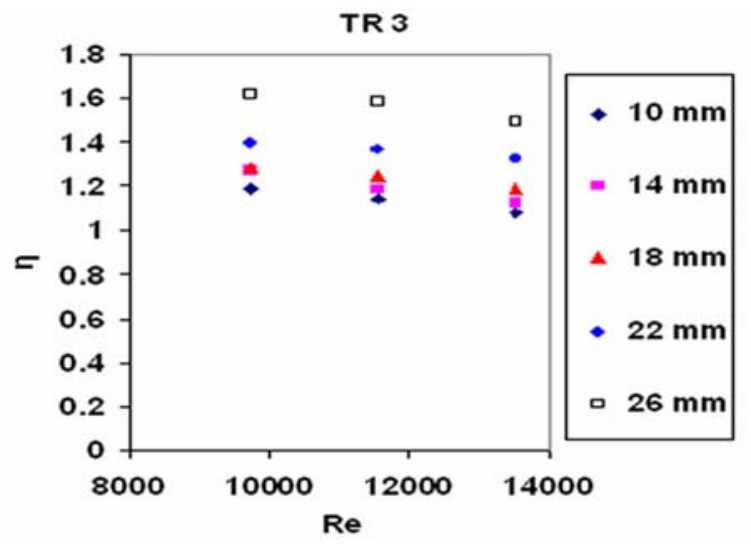

Figure 10: Variation of Overall enhancement with Reynolds number for twist ratio=3

It is seen in Figure 10 that, for tapes of widths $26,22,18,14$ and $10 \mathrm{~mm}$ curves are of decreasing order $(\eta=1.0-2.0)$ for a pitch of $82.5,110$ and $137.5 \mathrm{~mm}$ in the range of Reynolds number from 8000 to 14000 . The tapes of width $22 \mathrm{~mm}$ perform more or less like full-width tapes for twist ratio equal to $3(82.5 \mathrm{~mm}$ pitch). The reduction in Nusselt number for $22 \mathrm{~mm}$ width tape was found to be $8 \%$ compared to that of full width tape. This is comparable with the experimental results obtained by (Patil, 2000) where percentage reduction in Nusselt numbers varied from 5-9\% for reduced width twisted tape inserts.

It is observed from Figure 11 and 12, that even the tapes of $10 \mathrm{~mm}$ width have an $\eta$ value of about 1.08-1.18 times over the plain tube. The gradual reduction of these curves basically represents the same performance of reduced width tapes as that of the fullwidth tape. Thus the same performance can be achieved using reduced width tapes with $15 \%-61 \%$ material saving at higher Reynolds number and/or lower twist ratios. For $61 \%$ material savings (tapes of width $22 \mathrm{~mm}$ ), the performance is $1.32-1.39$ times better than for a plain tube. This is comparable with results obtained by (Patil, 2000) in which, material savings varied from 20 to $50 \%$.

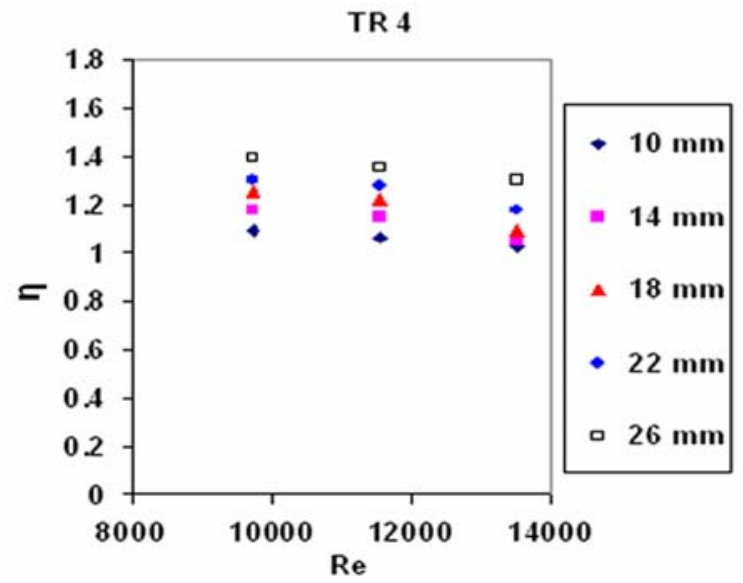

Figure 11: Variation of Overall enhancement with Reynolds number for twist ratio=4

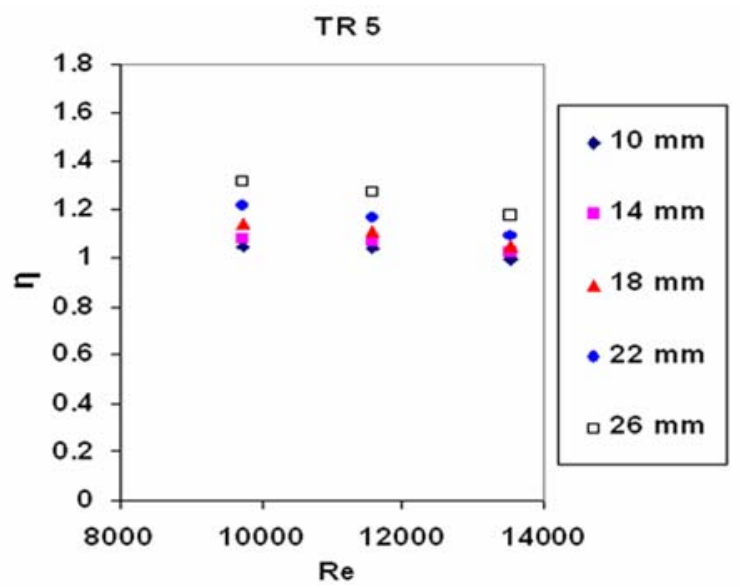

Figure 12: Variation of Overall enhancement with Reynolds number for twist ratio $=5$ 


\subsection{Heat Transfer Correlations:}

The present experimental results of the Nusselt number and friction factor are correlated in terms of Reynolds number and modified twist ratio as follows:

$$
N u=0.4141 * 10^{-4} * \operatorname{Re}^{0.9591}\left[(0.001+H / w)^{-0.04645}\right] *\left(D_{h} / L\right)^{-1.411}
$$

Average deviation $=6.246 \%$ and standard deviation $=7.983 \%$

$$
f=0.01391 * R^{-0.1374}\left[(0.001+H / w)^{-0.003}\right] *\left(D_{e} / L\right)^{-0.2097}
$$

Average deviation $=2.216 \%$ and standard deviation $=2.692 \%$

Eq. (15) and (16) are applicable when $3.17<H / w<61,0.02<D_{e} / L<0.03$ and $6000<R e<13500$

When $D_{h}=D$ and $H / w=0$; Eq. 15 and 16 are applicable to plain tube also.

\section{Conclusions}

The study presents an experimental investigation of the potential of reduced width twisted tape inserts to enhance the rate of heat transfer in a horizontal circular tube with inside diameter $27.5 \mathrm{~mm}$ with air as working fluid. The Reynolds number varied from 6000 to 13500 . The effects of parameters such as modified twist ratio, Reynolds number on the heat transfer and overall enhancement ratio are studied.

The following conclusions can be drawn:

$>$ The enhancement of heat transfer with twisted tape inserts as compared to plain tube varied from 36 to $48 \%$ for full width and 33 to $39 \%$ for reduced width- $22 \mathrm{~mm}$ inserts. This enhancement is mainly due to the centrifugal forces resulting from the spiral motion of the fluid.

$>$ Reduction in tape width causes reduction in Nusselt numbers as well as friction factors. The maximum friction factor rise was about $18 \%$ for $26 \mathrm{~mm}$ and only $17.3 \%$ for reduced width inserts compared to plain tube.

$>$ The over all enhancement ratio of the tubes with full width twisted tape inserts is 1.62 for full width-26mm and 1.39 for reduced width-22mm twisted tape insert.

$>61 \%$ material savings could be obtained for reduced width- $22 \mathrm{~mm}$ and the performance is $1.32-1.39$ times compared to plain tube.

$>$ Nusselt numbers decreased by a maximum of $8 \%$ and $29 \%$, for tape widths of 22 and $10 \mathrm{~mm}$, respectively compared to full width twisted tape inserts. The present work is comparable with the experimental results obtained by (Patil, 2000) on laminar flow heat transfer enhancement using reduced width twisted tape inserts

$>$ Correlations for the heat transfer coefficient and friction factor are proposed based on the present experimental data. The agreement between the results obtained from the experimental and those obtained from the proposed correlations is reasonable.

Thus the same performance can be achieved using reduced width tapes with $15 \%$ material saving at higher Reynolds number and/or lower twist ratios. Even for $61 \%$ material savings twisted tapes (of width $10.0 \mathrm{~mm}$ ) the performance is $1.08-1.18$ times better than for a smooth tube. Thus, from the considerations of enhanced heat transfer and savings in pumping power and in tape material cost, reduced-width tape inserts are seen to be attractive for enhancing turbulent flow heat transfer in a horizontal circular tube.

Future work may be extended to:

- Change the tape material from Aluminium to Copper

- Compound enhancement techniques maybe applied i.e., the tape inserts can be coupled with coil wire inserts for better enhancement

- Other reduced width twisted tapes along with variation in Reynolds numbers; and

- Develop further correlations by considering lower Reynolds numbers

\section{Nomenclature}

A convective heat transfer area $(\pi D L),\left(\mathrm{m}^{2}\right)$ 


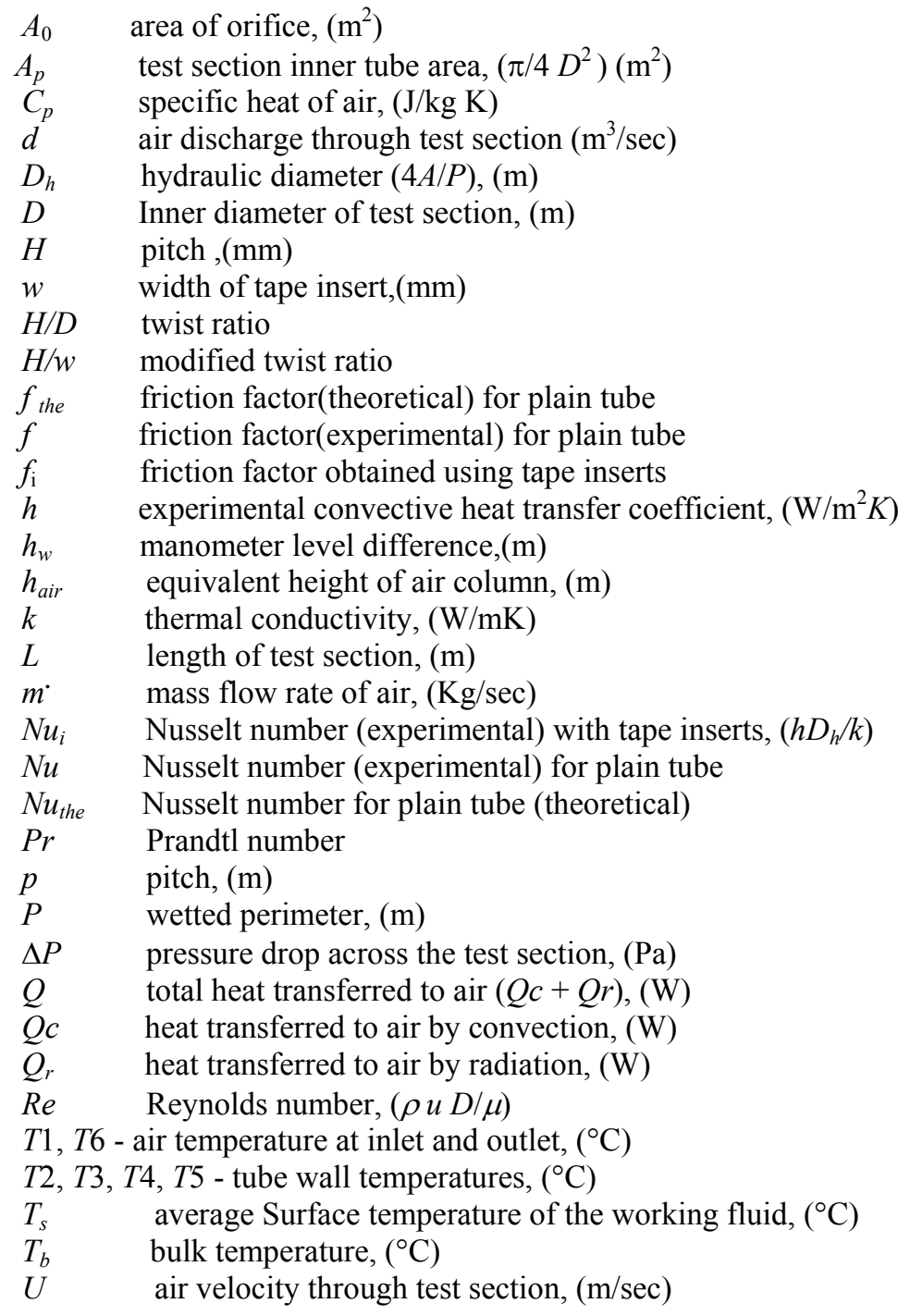

Greek symbols

$v \quad$ Kinematic viscosity of air, $\left(\mathrm{m}^{2} / \mathrm{sec}\right)$

$\varepsilon_{C} \quad$ emissivity of Copper

$\mu \quad$ dynamic viscosity, $(\mathrm{kg} / \mathrm{m} \mathrm{s})$

$\eta \quad$ Over all enhancement ratio

$\rho_{w} \quad$ density of water, $\left(\mathrm{Kg} / \mathrm{m}^{3}\right)$

$\rho_{a} \quad$ density of air $\left(\mathrm{Kg} / \mathrm{m}^{3}\right)$

\section{References}

Al-Fahed S, and Chakroun W, 1996. Effect of tube -tape clearance on heat transfer for fully developed turbulent flow in a horizontal isothermal tube, Int. J. Heat Fluid Flow, Vol. 17, No. 2, pp. 173-178.

Al-Fahed S, Chamra L.M, and Chakroun W, 1998. Pressure drop and heat transfer comparison for both microfin tube and twistedtape inserts in laminar flow, Experimental Thermal Fluid Science, Vol. 18, No. 4, pp. 323-333.

Akhavan-Behabadi M.A, Ravi Kumar, Mohammadpour .A and Jamali-Asthiani .M, 2009. Effect of twisted tape insert on heat transfer and pressure drop in horizontal evaporators for the flow of R-134a, International Journal of Refrigeration, Vol. 32, No. 5, pp. 922-930.

Akhavan-Behabadi M. A., Ravi Kumar and A. Rajabi-Najar, 2007. Augmentation of heat transfer by twisted tape inserts during condensation of R-134a inside a horizontal tube, Heat and Mass Transfer, Vol. 44, No. 6, pp. 651-657 
Chang S.W, Yang T.L, Liou J.S, 2007. Heat transfer and pressure drop in tube with broken twisted tape insert, Experimental Thermal and Fluid Science, Vol. 32, No. 2, pp. 489-501.

Chang S.W., Jan Y.J, Liou J.S., 2007. Turbulent heat transfer and pressure drop in tube fitted with serrated twisted tape, International Journal of Thermal Sciences, Vol. 46, No. 5, pp. 506-518.

Dasmahapatra J. K, and Raja Rao M, 1991. Laminar Flow heat transfer to generalized power law fluids inside circular tubes fitted with regularly spaced twisted tape elements for uniform wall temperature condition, Fundamentals of Heat Transfer in NonNewtonian Fluids, ASME, New York, pp. 51-58.

Eiamsa-ard .S, Nivesrangsan P, Chokphoemphun.S, Promvonge.P, 2010a. Influence of combined non-uniform wire coil and twisted tape inserts on thermal performance characteristics, International Communications in Heat and Mass Transfer, Vol. 37 , No. 7, pp. 850-856

Eiamsa-ard S., Thianpong C., Eiamsa-ard P., Promvonge P., 2010b. Thermal characteristics in a heat exchanger tube fitted with dual twisted tape elements in tandem, International Communications in Heat and Mass Transfer, Vol. 37, pp. 39-46

Eiamsa-ard S., Thianpong C., Eiamsa-ard P., Promvonge P., 2009. Convective heat transfer in a circular tube with short-length twisted tape insert, International Communications in Heat and Mass Transfer, Vol. 36, pp. 365-371.

Jaisankar.S, Radhakrishnan T.K., Sheeba K.N. and Suresh S., 2008. Experimental studies on heat transfer and friction factor characteristics of thermosyphon solar water heater system fitted with left-right twisted tapes, International Journal of Applied Engineering Research, Vol. 3, No. 8, pp. 1091-1103.

Kumar R., Mohammadpoura A. and Jamali-Asthiania M., 2009. Effect of twisted tape insert on heat transfer and pressure drop in horizontal evaporators for the flow of R-134a, International Journal of Refrigeration, Vol. 32, No. 5, pp. 922-930.

Lin Z.-M., Sun D.-L. and Wang L.-B., 2009. The relationship between absolute vorticity flux along the main flow and convection heat transfer in a tube inserting a twisted tape, Heat and Mass Transfer, Vol. 45, No. 11, pp. 1351-1363.

Manglik R.M and Bergles A.E, 1992. Heat transfer enhancement and pressure drop in viscous liquid flows in isothermal tubes with twisted-tape inserts, Heat and Mass Transfer, Vol. 27, No. 4, pp. 249-257

Monheit. M, 1987. Experimental evaluation of the convective characteristics of tubes with twisted tape inserts, Advances in Enhanced Heat Transfer, AMSE, New York, pp. 11-18.

Murugesan .P, Mayilsamy.K, Suresh .S, Srinivasan .P.S.S, 2009. Heat transfer and pressure drop characteristics of turbulent flow in a tube fitted with trapezoidal-cut twisted tape insert, International Journal of Academic Research, Vol. 1, No. 1, pp. 123-128

Patil A.G, February 2000, Laminar flow heat transfer and pressure drop characteristics of power-law inside tubes with varying width twisted tape inserts, ASME Transactions, Vol. 122, pp. 143-149.

Naphon P., 2006. Heat transfer and pressure drop in the horizontal double pipes with and without twisted tape insert, International communications in Heat and Mass Transfer, Vol. 33, pp. 166-175.

Promvonge P. and Eiamsa-ard S., 2007. Heat transfer behaviors in a tube with combined conical-ring and twisted-tape insert, International Communications in Heat and Mass Transfer, Vol. 34, pp. 849-859.

Raj M. Manglika and Arthur E. Bergles, 2003. Swirl flow heat transfer and pressure drop with twisted-tape inserts, Advances in Heat Transfer, Vol. 36, pp. 183-266.

Rahimi .M, Shabanian S.R., Alsairafi A.A., 2009. Experimental and CFD studies on heat transfer and friction factor characteristics of a tube equipped with modified twisted tape inserts, Chemical Engineering and Processing, Vol. 48, pp. 762-770

Saha S.K and Mallick D. N., September 2005. Heat transfer and pressure drop characteristics of laminar flow in rectangular and square plain ducts and ducts with twisted-tape inserts, Transactions of the ASME, Vol. 127.

Sarma P.K, Subramanyam T., Kishore P.S, Dharma Rao V, Sadik Kakac, 2003. Laminar convective heat transfer with twisted tape inserts in a tube, International Journal of Thermal Sciences, Vol. 42, pp. 821-828.

Sivashanmugam .P and P.K. Nagarajan, 2007. Studies on heat transfer and friction factor characteristics of laminar flow through a circular tube fitted with right and left helical screw-tape inserts, Experimental Thermal and Fluid Science, Vol. 32, No. 1, pp. 192-197.

Sivashanmugam .P and Suresh .S, 2006. Experimental studies on heat transfer and friction factor characteristics of laminar flow through a circular tube fitted with helical screw-tape inserts, Applied Thermal Engineering, Vol. 26, No. 16, pp. 1990-1997

Sivashanmugam P., Suresh .S, 2007. Experimental studies on heat transfer and friction factor characteristics of turbulent flow through a circular tube fitted with helical screw-tape inserts, Chemical Engineering Process, Vol. 46, pp. 1292-1298.

Shou-Shing Hsieh, I.W.Huang, 2000. Heat transfer and pressure drop of laminar flow in horizontal tubes with/without longitudinal inserts, Journal of Heat Transfer, Vol.122, pp. 465-475.

Shou-Shing Hsieh, Ming-Ho Liu, Huang-Hsiu Tsai, 2003. Turbulent heat transfer and flow characteristic in a horizontal circular tube with strip-type inserts Part-I (Fluid mechanics), International Journal of Heat and Mass Transfer, Vol. 46, pp. 823-835.

Wongchareeb, P. Eiamsa-ardc and C. Thianpongc, 2010. Heat transfer enhancement in a tube using delta-winglet twisted tape inserts, Applied Thermal Engineering, Vol. 30, No. 4, pp. 310-318.

\section{Biographical notes}

S. Naga Sarada received M. Tech. from Jawaharlal Nehru Technological University, Hyderabad, India in 1996. She is an Associate Professor in the Department of Mechanical Engineering, JNTUH College of Engineering, Hyderabad, Andhra Pradesh, India. She is having more than 13 years of experience in teaching and R 
and D. Her research interests include Heat Transfer, Thermal Engineering and CFD. She has published more than 10 papers in international journals. She has also presented more than 10 research articles in National and International conferences. She is a Life member of ISHMT and ISTE.

Dr. A.V.Sita Rama Raju is a Professor in the Department of Mechanical Engineering, JNTUH College of Engineering, Hyderabad, Andhra Pradesh, India. He has more than 20 years of experience in teaching and research. His current area of research includes IC Engines, Thermal Engineering, Combustion modeling and Alternate fuels. He has published more than 22 papers in referred international journals. He has also presented more than 20 research articles in National and International conferences. He is member of ISTE, LMC, etc.

Dr. K. Kalyani Radha received M. Tech. and Ph.D from Jawaharlal Nehru Technological University, Hyderabad, India in 2004 and 2009 , respectively. She is presently working as a Principal, Sri Sai College of Engineering and Technology, Anantapur, Andhra Pradesh, India. She is having around 10 years of experience in teaching and Research. Her research interests include IC Engines, Combustion modeling, Alternate fuels, Heat transfer, Refrigeration and Air-conditioning. She has published more than 8 papers in International journals. She has also presented more than 10 research articles in National and International conferences. She is a Life member of LMC, ISHMT and ISTE.

L. Shyam Sunder received M. Tech. from Jawaharlal Nehru Technological University, Hyderabad, India in 2006. He is an M.Tech Student, JNTUH College of Engineering, Hyderabad, Andhra Pradesh, India. His research interests include Heat transfer, Nanotechnology and Thermal Engineering.

Received July 2010

Accepted September 2010

Final acceptance in revised form September 2010 